\title{
Structures and Physical Properties of Cross-Linked Gelatin Fibers
}

\author{
Masanobu Nagura, ${ }^{\dagger}$ Hirosi YoKota, Mayumi IKeURA, \\ Yasuo Gotoh, and Yutaka OHKOSHI \\ Faculty of Textile Science and Technology, Shinshu University, \\ 3-15-1 Tokida, Ueda 386-8567, Japan
}

(Received May 13, 2002; Accepted August 8, 2002)

\begin{abstract}
This study aims to prepare a practical gelatin fiber suitable for use as a cross-linked suture. Various gelatin fibers were created in different ways: by cross-linking using heat $(\mathrm{H})$; by cross-linking with carbonic acid (CA), namely citric acid; and by cross-linking with either of two epoxy compounds: ethylene glycol diglycidyl ether (E) and diglycerol triglycidyl ether (D). For each fiber type was produced at several different $\mathrm{pH}$ levels $(7,8,10$, and 12) in order to measure changes in the rate at which the amino group reacted with the epoxy group. E and D swelled more than $\mathrm{H}$ and CA did, and D swelled more than $\mathrm{E}$ and at every $\mathrm{pH}$, D swelled more than $\mathrm{E}$ did. The cross-linking densities of $\mathrm{E}$ and $\mathrm{D}$ fibers reached a minimum at $\mathrm{pH} 8$, corresponding to the degree of swelling. The stresses at a strain of $50 \%$ for $\mathrm{E}$ and $\mathrm{D}$ reached a minimum at $\mathrm{pH} 8$. The toughest fiber, which has the largest surrounded area between stress and strain, was the cross-linked $\mathrm{E}$ at $\mathrm{pH} 12$.

KEY WORDS Cross-Link / Gelatin / Fiber / Carbonic Acid / Diepoxide Compound / Swelling /

Fracture /
\end{abstract}

Although collagen is expensive, it is a very important protein as a biomaterial, because it has a high rate of cell growth on its surface ${ }^{1}$ and is biodegradable. ${ }^{2}$ Collagen has therefore served as a cell culture substrate and as a tissue substitute.

Although low production cost makes it seem convenient to use gelatin regenerated from collagen as a biomaterial, there are three problems with the use of such gelatin: it dissolves at the temperature of the human body, it causes antigen-antibody reactions ${ }^{3}$ and prion proteins can be contaminated by Bovine Spongiform Encephalopathy (BSE). ${ }^{4}$

The chemically cross-linked gelatin will not dissolve when heated, and is useful as a biomaterial. Murabayashi et al. ${ }^{5}$ prepared a gelatin-coated polyurethane membrane that was grafted. This membrane showed excellent blood compatibility. Yoshizato et al. ${ }^{6}$ made a porous gelatin membrane that was crosslinked with a compound, i.e., with a cross-linker. This compound had two epoxy groups and showed excellent cell growth on the surface as well as biocompatibility. In a previous study we tried to prepare another membrane with a cross-linker containing two or three carbonyl groups. We also studied the growth of cultured L929 cells derived from mouse connective tissue fibroblast, and clarified that the rate of growth of those cells was similar to that on collagen-coated polystyrene film. ${ }^{7,8}$ These results mean that chemically cross-linked gelatin is useful as a tissue substitute. It is considered that cross-linking using amino groups in gelatin molecules is also effective for preventing an

${ }^{\dagger}$ To whom correspondence should be addressed. antigen-antibody reaction, by virtue of the presence of an amino group in the side chain. Furthermore, even if the prion protein contaminates the gelatin, the prion will be cross-linked by using amino groups such as lysine, asparagine and glutamine in the protein ${ }^{9}$ with epoxy and carbonic acid compounds. This will prevent the protein from becoming an abnormal prion.

It is well known that gelatin is also useful as a biodegradable material, e.g., as a food. Gelatin fibers are therefore expected to find use as biodegradable sutures that are biocompatible as described above. No one, however, has successfully prepared a practical gelatin fiber.

This study aims to prepare a practical gelatin fiber as a cross-linked suture.

\section{EXPERIMENTAL}

The gelatin used in this study, kindly supplied by Nitta Gelatin Co. Ltd., Japan, was derived from cattle bones gelatinized with alkali. This study used two types of cross-linking agents, called cross-linkers. One type includes a tri-carbonic acid compound, namely citric acid, purchased from Wako Co., Japan, without any purification. The other type of cross-linker includes two multi-functional epoxy compounds: ethylene glycol diglycidyl ether (EGDE) and diglycerol triglycidyl ether (DTE), purchased from Nagase Chem. Tec. Co., Japan. The chemical structure of each cross-linker is shown in Table I. These cross-linkers will react with the amino group in the gelatin to carry out the objectives described in the introduction. 
Table I. Chemical structure of cross-linker

Citric acid (CA)
Ethylene glycol diglycidyl ether
(EGDE)
Diglycerol triglycigyl ether
(DTE)

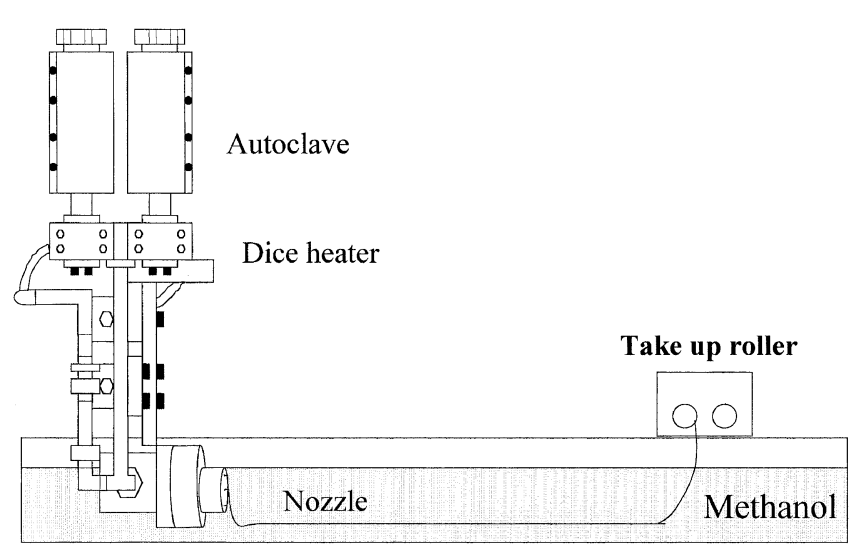

Figure 1. Schematic drawing of wet spinning apparatus.

Three types of cross-linked gelatin fibers were produced according to the following procedures.

(1) A $20 \mathrm{wt} \%$ aqueous solution of gelatin at $40^{\circ} \mathrm{C}$ was spun in methanol at $20^{\circ} \mathrm{C}$ by using the wet spinning apparatus shown in Figure 1, with a nozzle diameter $0.5 \mathrm{~mm}$. The resulting fiber was heated in an oven in vacuum at $150^{\circ} \mathrm{C}$ for $3 \mathrm{~h}$ to cross-link. ${ }^{10}$ We named this fiber $\mathrm{H}$.

(2) A $20 \mathrm{wt} \%$ aqueous solution of gelatin was mixed with citric acid in an amount equal to the mol of the amino group in the gelatin. The mixture at $40^{\circ} \mathrm{C}$ was spun in the same way as described above. The resulting fiber was cured in an oven in vacuum at $150^{\circ} \mathrm{C}$ for $3 \mathrm{~h}$ to cross-link. We named this fiber CA.

(3) A $20 \mathrm{wt} \%$ aqueous solution of gelatin at $40^{\circ} \mathrm{C}$ was spun under the same conditions as above, and then the gelatin fiber was immersed in the mixture $\{1 / 9$ $(\mathrm{w} / \mathrm{w})\}$ of the epoxy compound (as the cross-linker) and solvent $\{$ water/methanol $(6 / 4)\}$ for $3 \mathrm{~h}$ at $20^{\circ} \mathrm{C}$, at $\mathrm{pH} 7,8,10$, and 12 to change the reaction rate of the amino group with the epoxy group. ${ }^{11}$ After immersion, the cross-linked gelatin was dried in air atmosphere. We named the fibers cross-linked with EGDE and DTE $\mathrm{E}$ and $\mathrm{D}$, respectively.

The reaction ratio of the amino group of gelatin with the epoxy group of the cross-linker was estimated by the TNBS method. ${ }^{12}$ The reaction ratio $(X)$ was calculated by using eq 1 ,

$$
X=100\left(S_{\mathrm{u}}-S_{\mathrm{r}}\right) / S_{\mathrm{u}}
$$

where $S_{\mathrm{u}}$ and $S_{\mathrm{r}}$ are the absorption intensities at $345 \mathrm{~nm}$ of UV spectra before and after the cross-linkage, respectively. UV spectra were measured by using a Hitachi U-3500 at 300 to $450 \mathrm{~nm}$, with a scanning speed of $300 \mathrm{~nm} \mathrm{~min}{ }^{-1}$.

The degree of swelling was calculated using eq 2 and assuming the swelling would be isotropic because the fiber was not oriented toward fiber axis.

$$
S=\left(L_{\mathrm{s}} / L_{\mathrm{d}}\right)^{3}
$$

where $L_{\mathrm{d}}$ and $L_{\mathrm{s}}$ are the length of the cross-linked fiber before and after swelling, respectively. Swelling was measured in water at $40^{\circ} \mathrm{C}$ for $1 \mathrm{~h}$.

Mechanical properties were measured by using a Tensilon, UTM-4L (Toyo Sokki Co., Ltd.), at a crosshead speed of $40 \mathrm{~mm} \mathrm{~min}{ }^{-1}$. The equilibrium stress was measured at strains of 20,40,60,80, and $100 \%$.

To obtain the storage modulus, dynamic mechanical thermal analysis (DMTA) was carried out with an ITK Co. DVA-225 in a stretching mode with a frequency of $10 \mathrm{~Hz}$ and at a heating rate of $5^{\circ} \mathrm{C} \mathrm{min}^{-1}$.

\section{RESULTS AND DISCUSSION}

The degree of swelling depended heavily on the cross-linker used. Figure 2 shows the degree to which each of the cross-linked fibers swelled. E and D swelled more than $\mathrm{H}$ and $\mathrm{CA}$ did, indicating that $\mathrm{E}$ and $\mathrm{D}$ had relatively low cross-linking densities. In every $\mathrm{pH}$ case, $\mathrm{D}$ swelled to a greater degree than $\mathrm{E}$ did. This was because DTE contained a hydrophobic $\mathrm{OH}$ group. For both $\mathrm{E}$ and $\mathrm{D}$ fibers, the degree of swelling reached a maximum when the mixture of the cross-linker and the solvent was at $\mathrm{pH} 8$. This means that the degree of cross-linking reached a minimum at $\mathrm{pH} 8$. Therefore, it is necessary to know how the degree of swelling relates to cross-link density.

Figure 3 shows the reaction rates of amino groups in gelatin with the carboxyl and epoxy groups of the various cross-linkers. The reaction rate of CA is higher than 


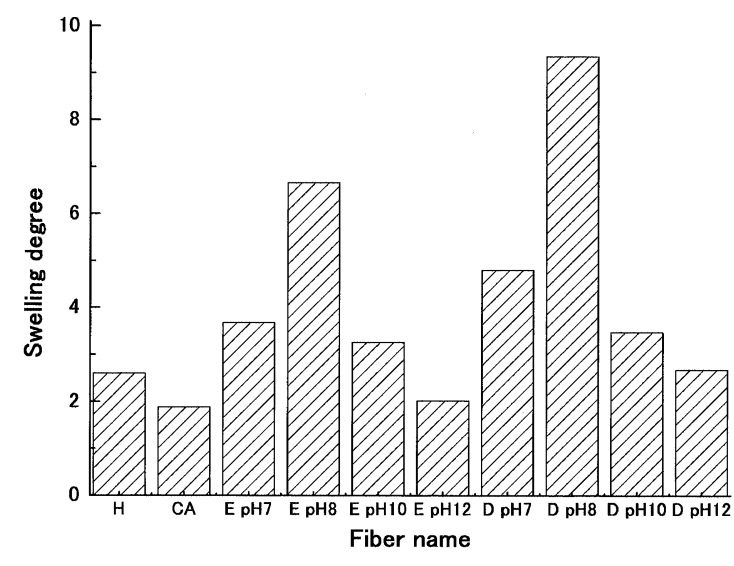

Figure 2. Swelling degree of cross-linked fiber.

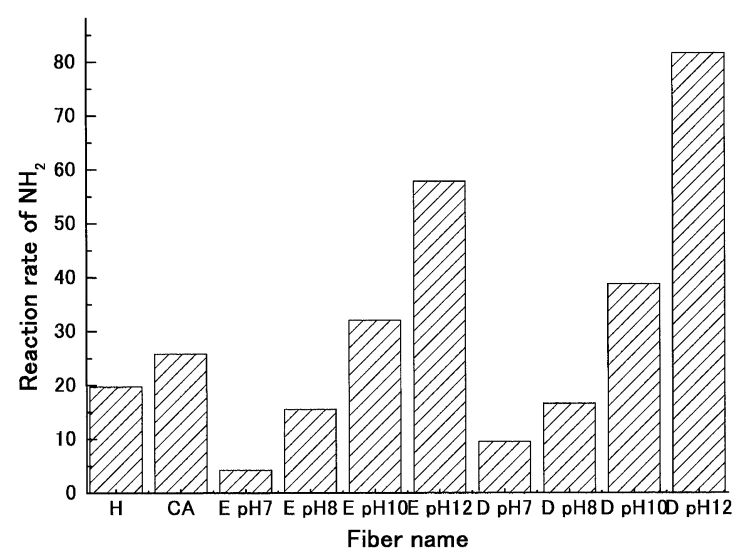

Figure 3. Reaction rate of amino groups of gelatin with carboxyl group and epoxy group of cross-linker.

that of $\mathrm{H}$, because the mixed citric acid has three carbonic acids as functional groups, so these groups crosslink easily with the amino group in gelatin. The reaction rates for $\mathrm{E}$ and $\mathrm{D}$ increase as $\mathrm{pH}$ increases. There is a discrepancy between the reaction rate of the amino group and the degree of swelling, as seen Figure 2. This discrepancy occurs because stress depends directly on the entropy-elasticity of the molecules between crosslink points for the hydrogel. The reason for the discrepancy is probably clarified by the cross-linking density, which we evaluated by measuring the stress-strain relation of the cross-linked fibers swollen in water.

Figures $4 \mathrm{a}, 4 \mathrm{~b}$, and $4 \mathrm{c}$ show the dependence of stress, $\sigma\left(\mathrm{Nm}^{-2}\right)$, on $\lambda-\lambda^{-2}$, where $\lambda$ is the elongation ratio. All data are linear at below 0.4 of $\lambda-\lambda^{-2}$, namely $\lambda=$ 1.15. This indicates that every cross-linked fiber satisfies the equation of ideal rubber elasticity in this region. Therefore we can estimate the cross-linking density, $n_{\mathrm{c}}$, (Number $\mathrm{m}^{-3}$ ), by using eq 3 of ideal rubber elasticity, ${ }^{13}$

$$
\sigma=n_{\mathrm{c}} k T\left(\lambda-\lambda^{-2}\right)
$$

where $k$ is Boltzman's constant, $1.38 \times 10^{-23}$ $\left(\mathrm{N} \mathrm{m} \mathrm{K}^{-1}\right), \quad T$ is absolute temperature $(\mathrm{K})$, which in this study is $313(\mathrm{~K})$. The calculated cross-linking

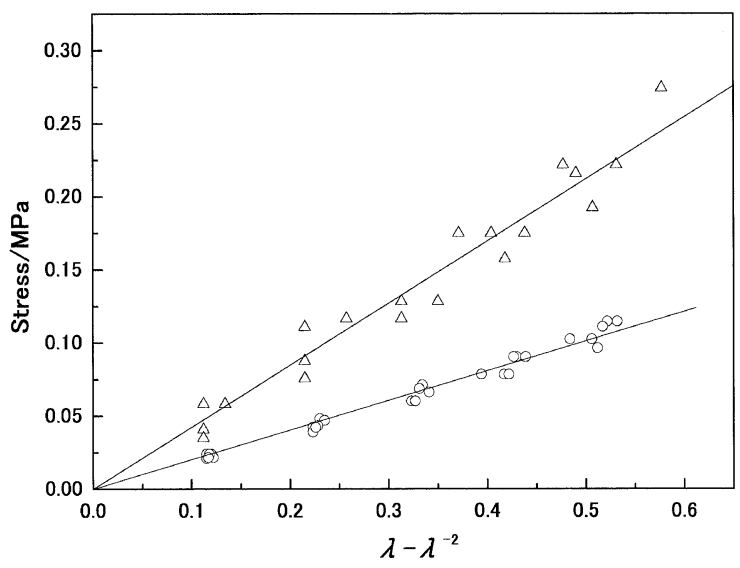

(a)

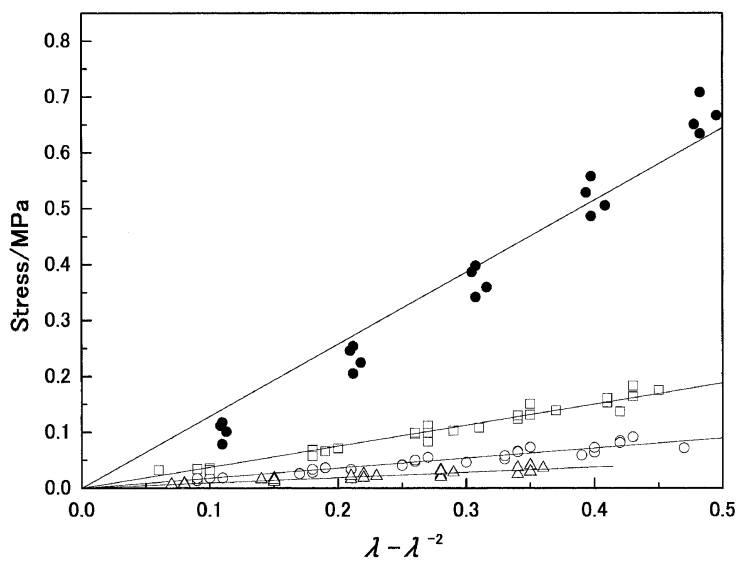

(b)

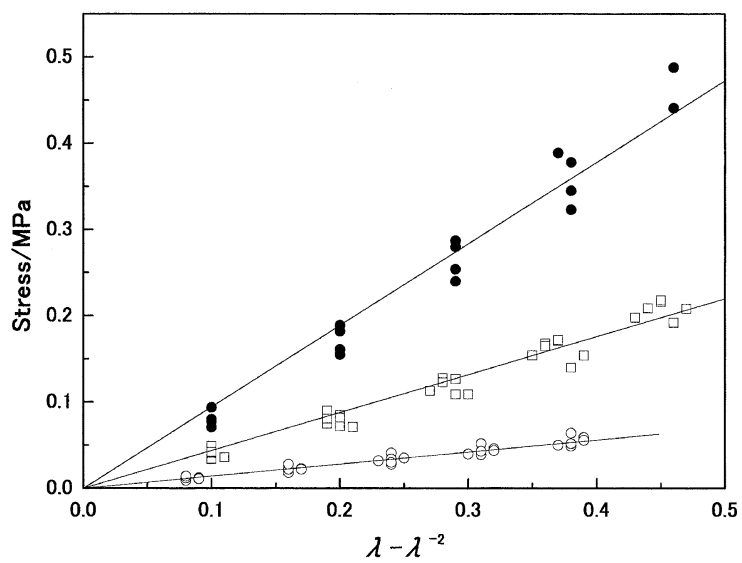

(c)

Figure 4. Dependence of stress, $\sigma$, on $\lambda-\lambda^{-2}$, (a) $\mathrm{H}$; - - $\mathrm{CA} ;-\triangle-$, (b) $\mathrm{E}: \mathrm{pH} 7$; $\bigcirc-, \mathrm{pH} 8 ;-\triangle-, \mathrm{pH} 10 ;-\square-$, $\mathrm{pH} 12$;

, (c) D: $\mathrm{pH} 7 ;-\bigcirc-, \mathrm{pH} 10 ;-\square-, \mathrm{pH} 12 ;$

densities are shown in Figure 5. The cross-linking density of CA is larger than that of $\mathrm{H}$. This corresponds to the differences in the reaction rate of the amino group with the carboxyl group as the cross-linking point, as seen in Figure 3. The cross-linking densities of $\mathrm{E}$ and $\mathrm{D}$ reach a minimum at $\mathrm{pH} 8$, indicating correspondence with the swelling degree. It is known that the carbonyl group reacts easily with the epoxy group at low $\mathrm{pH}$. This suggests that at $\mathrm{pH} 7$, the epoxy 


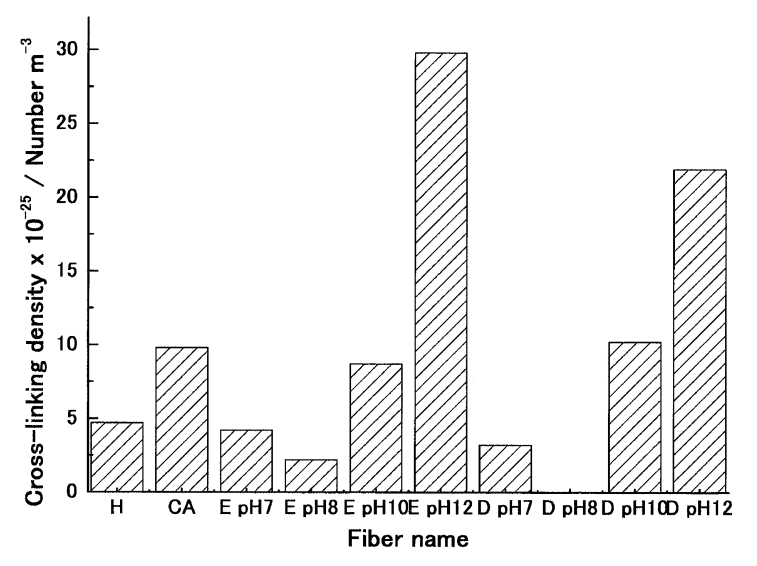

Figure 5. Cross-linking density of cross-linked fibers.

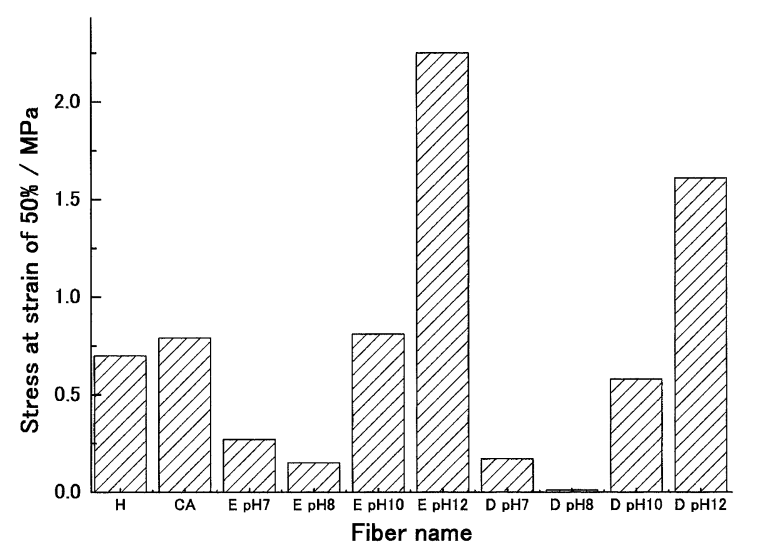

Figure 6. Dependence of stress at strain of $50 \%$ for crosslinked fibers.

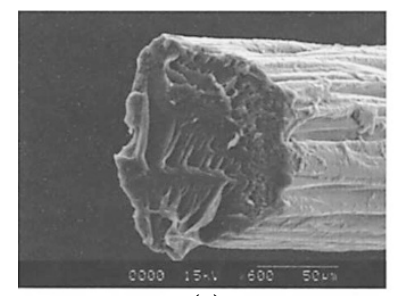

(a)

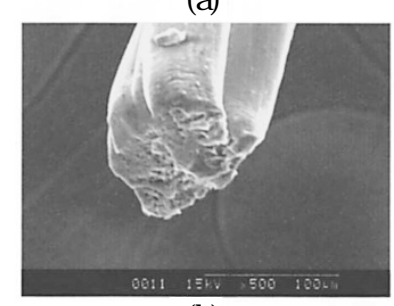

(b)

Figure 7. SEM photographs, (a) uncross-linked dried E, (b) cross-linked $\mathrm{E}$ at $\mathrm{pH}$ 7, (c) wet fiber of cross-linked $\mathrm{E}$ at $\mathrm{pH}$ 7.

group will react not only with the carbonyl group but also with the amino group. This result of the cross-linking density will be related to the mechanical property of the cross-linked gelatin hydrogel fiber.

Figure 6 shows the stress at a strain of $50 \%$ for the cross-linked fibers. The stress of CA is larger than that of $\mathrm{H}$ because of the higher cross-linking density of the former. Furthermore, the stresses of $\mathrm{H}$ and $\mathrm{CA}$ are

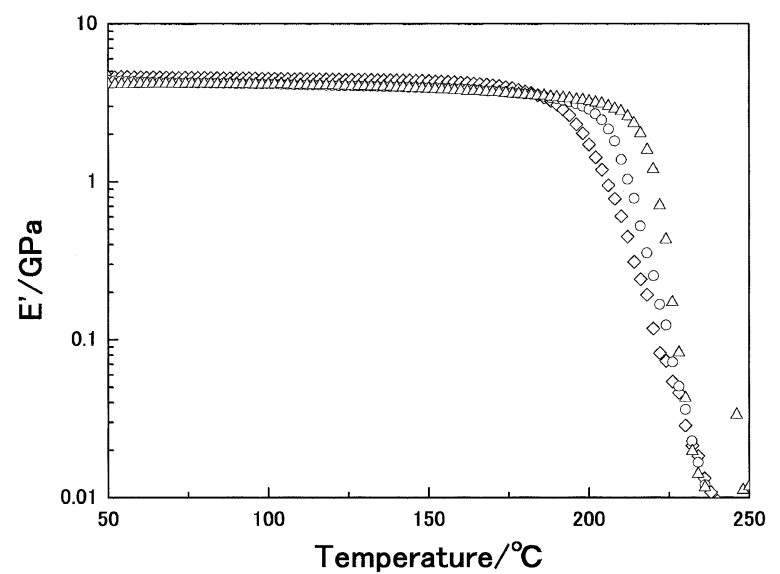

(a)

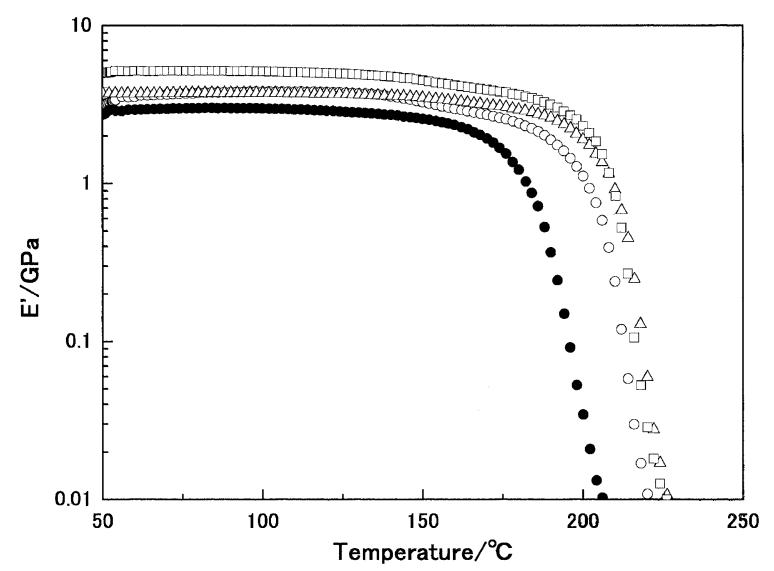

(b)

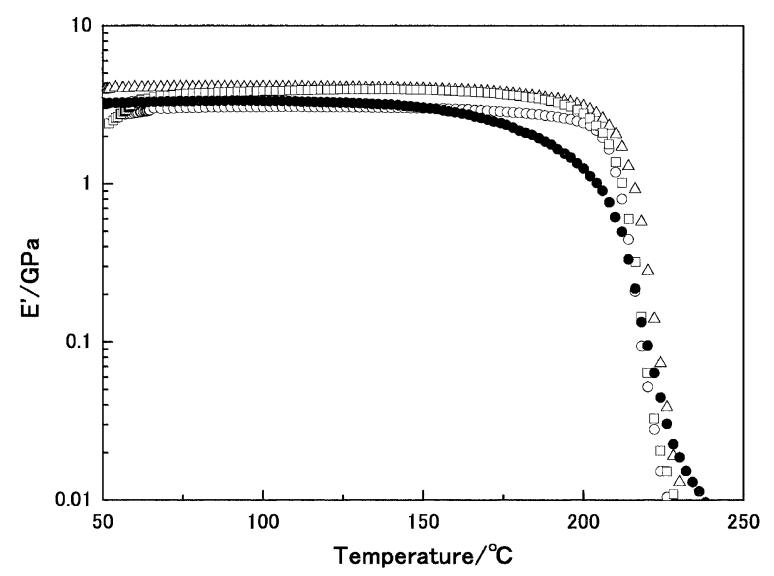

(c)

Figure 8. Dependence of storage modulus on temperature, (a) Uncross-linked gelatin; $-\diamond-, \mathrm{H} ;-\mathrm{O}-\mathrm{CA} ;-\triangle-$, (b) E: pH7; $-\mathrm{O}-\mathrm{pH} 8 ;-\triangle-, \mathrm{pH} 10 ;-\square-, \mathrm{pH} 12 ;-\bigcirc-$, (c) D: pH7; $-\mathrm{O}_{-} \mathrm{pH} 8 ;-\triangle-, \mathrm{pH} 10 ;-\square-, \mathrm{pH} 12 ;-\bigcirc-$.

lower than those of $\mathrm{E}$ and $\mathrm{D}$. This is probably caused by the high temperatures, at which those fibers become thermally decomposed. The stresses of E and D fibers reach a minimum at $\mathrm{pH} 8$. This result supports the above speculation. The stress of the swollen fiber crosslinked at $\mathrm{pH} 12$ is probably enough to make this fiber suitable for practical application as a cell culture substrate of woven or unwoven cloths. 


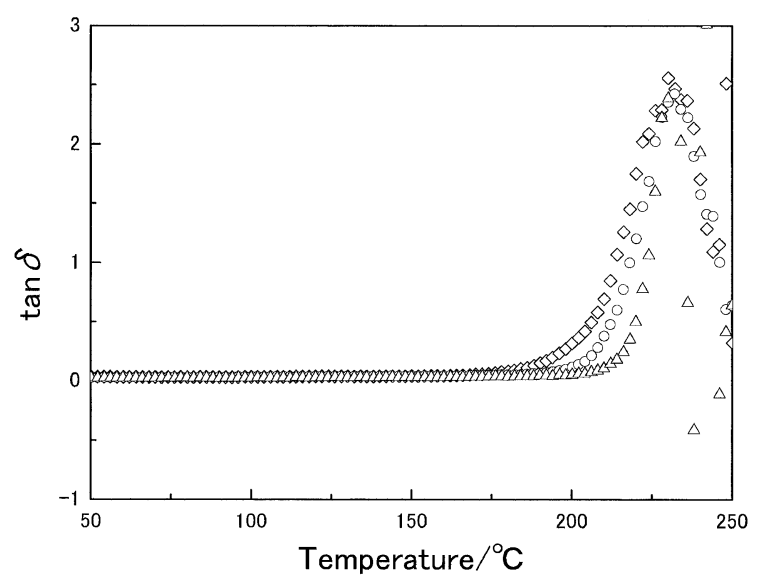

(a)

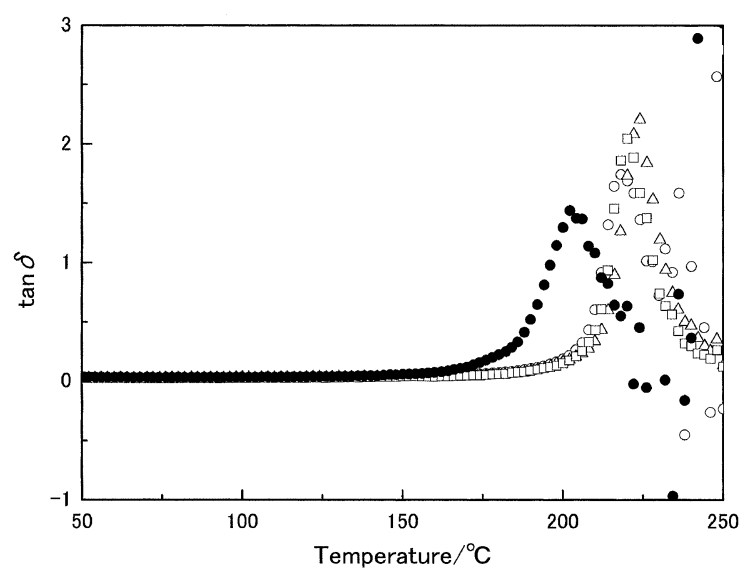

(b)

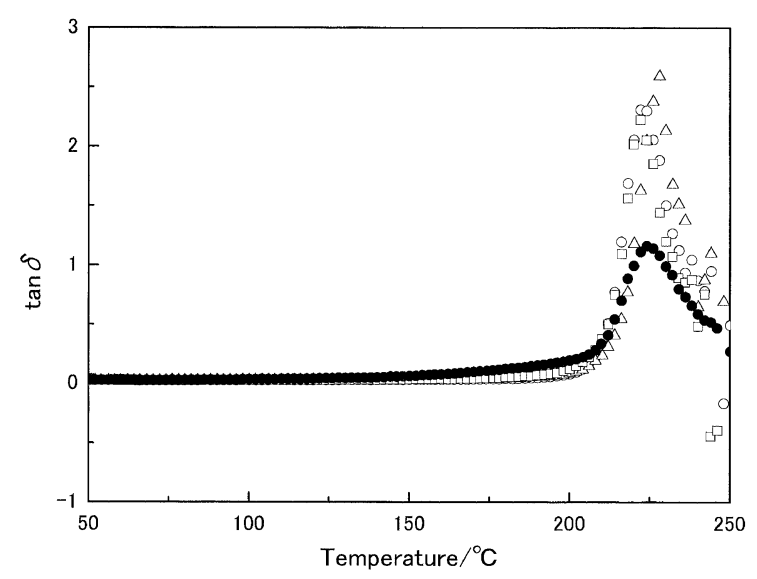

(c)

Figure 9. Dependence of $\tan \delta$ on temperature, (a) Uncrosslinked gelatin; $-\diamond-, \mathrm{H} ;-\bigcirc-, \mathrm{CA} ;-\triangle-$, (b) $\mathrm{E}: \mathrm{pH} 7-\bigcirc-$, $\mathrm{pH} 8 ;-\triangle-, \mathrm{pH} 10 ;-\square-, \mathrm{pH} 12 ;-\bigcirc-$, (c) $\mathrm{D}: \mathrm{pH} 7 ;-\bigcirc-$, $\mathrm{pH} 8 ;-\triangle-, \mathrm{pH} 10 ;-\square-, \mathrm{pH} 12 ;-\bigcirc-$

Figure 7 shows scanning electron microphotographs (SEM) of (A) dried non-cross-linked fiber, (B) dried cross-linked $\mathrm{H}$, and an optical microscope photograph of (C) wet cross-linked H. The dried fiber has many grooves on the surface, caused by dehydration in spinning into methanol, while the wet fiber has no grooves, because of swelling. Every SEM for other cross-linked

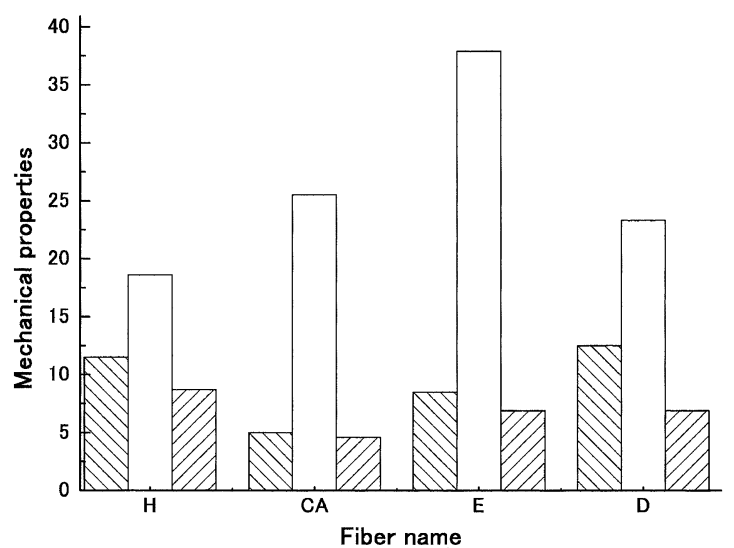

Figure 10. Mechanical properties of cross-linked fibers, $\square$; Fracture stress $\times 100 / \mathrm{GPa}, \square$; Fracture strain/\%, $\square$; Young's modulus/GPa.

fibers (not shown) looked like the SEMs in the figure.

Figures $8 \mathrm{a}, 8 \mathrm{~b}$, and $8 \mathrm{c}$ show the temperature dependence of the storage modulus, $\mathrm{E}^{\prime}$, for dried fibers. Above roughly $180^{\circ} \mathrm{C}$, every $\mathrm{E}^{\prime}$ of fiber decreases abruptly. In comparison with the uncross-linked gelatin fiber, $\mathrm{H}$ and $\mathrm{CA}$ decrease on the higher temperature side, while $\mathrm{E}$ and $\mathrm{D}$ with high cross-linking density decrease on the lower temperature side. This phenomenon is caused by lengthening the long-chain molecule or of the cross-linker; either of these would affect mobility more than they would affect the cross-linking density. Since gelatin has a glass transition temperature $\left(T_{\mathrm{g}}\right)$ at $196^{\circ} \mathrm{C}$, as determined by using a differential thermal analysis, this abrupt decrease in $\mathrm{E}^{\prime}$ change is due to the onset of the segmental motion of the amorphous chain between cross-linked points. The segmental motion can be observed as a peak in the dependence of $\tan \delta$ on temperature in the cases of crystalline polymers and cross-linked polymers. Figures 9a, 9b, and 9c show the temperature dependence of the $\tan \delta$. Every fiber shows a peak around $230^{\circ} \mathrm{C}$, which is about $35^{\circ} \mathrm{C}$ higher than in the case of $T_{\mathrm{g}}$. This means that the cross-link in the fibers is tightly formed by heating, because the weight loss of gelatin is about $3 \mathrm{wt} \%$ at $220^{\circ} \mathrm{C}$. Meanwhile, the temperature at which $\tan \delta$ increases is close to the decrease temperature of $\mathrm{E}^{\prime}$. Therefore, these results support that the molecular motion of cross-linkers occurs at lower temperatures than that of gelatin molecules in the case that $\mathrm{E}$ and $\mathrm{D}$ have high cross-linking as described above.

Figure 10 shows fracture stresses and strains as well as the Young's modulus of dried H, CA, E, and D. The toughest fiber, which has the largest surrounded area between stress and strain, was E cross-linked at $\mathrm{pH} 12$, and it could be knotted by hand. Therefore, E can probably serve as a suture fiber.

It should be studied in future to what extent these 
cross-linked gelatin fibers prevent the protein from becoming an abnormal prion.

Acknowledgments. The authors thank Nitta Gelatin Co. Ltd., Japan, for supplying the gelatin sample. This work was supported by a grant-in-aid for COE research (10CE2003) by the Ministry of Education, Culture, Sports, Science and Technology of Japan.

\section{REFERENCES}

1. R. L. Ehrmann and G. O. Gey, J. Nat. Cancer Inst., 16, 1375 (1956).

2. M. Takada, Jpn. J. Artif. Organs, 3, 169 (1966).

3. M. Sakaguchi, H. Ogura, and S. Inoue, J. Allergy Clin. Immunol., 96, 563 (1995).

4. Y. Ushiki, S. Hattori, and S. Irie, Fragrance Journal, 11, 21 (2001).
5. S. Murabayashi, H. Kambic, H. Harasaki, T. Morimoto, R. Yozu, and Y. Nose, Trans.-Am. Soc. Artif. Intern. Organs, 31, 50 (1985).

6. K. Yoshizato and E. Yoshikawa, Mater. Sci. Eng., C, 1, 95 (1994).

7. M. Nagura, M. Ikeura, Y. Gotoh, Y. Ohkoshi, and Y, Iwasaki, "6th World Biomaterials Congress", Preprint, 1298 (2000).

8. A. Ohtorii, M. Nagura, Y. Gotoh, Y. Ohkoshi, Y. Iwasaki, and N. Morimoto, Polym. Prepr., Jpn., 50, 832 (2001).

9. E. Turk, D. B. Teplow, L. E. Hood, and S. B. Prusiner, Eur. J. Biochem., 176, 21 (1988).

10. A. V. Tobolsky, Nature, 215, 509 (1967).

11. K. Kodaira, T. Miyata, M. Furusa, and Y. Noishiki, Jpn. J. Artif. Organs, 15, 239 (1986).

12. A. F. S. A. Habeeb, Anal. Biochem., 14, 328 (1966).

13. P. J. Flory, "Principles of Polymer Chemistry", Cornell University Press, Ithaca, N.Y., 1953, chapt. 11.

14. J. B. Yannas and A. V. Tobolsky, J. Macromol. Chem., 1, 723 (1966). 